\title{
Prognostic Implications of Gadolinium Enhancement of Skull Base Chordomas
}

\author{
(D)E. Lin, (D)T. Scognamiglio, (D) Y. Zhao, (D)T.H. Schwartz, and (D)C.D. Phillips
}

\begin{abstract}
BACKGROUND AND PURPOSE: Skull base chordomas often demonstrate variable MR imaging characteristics, and there has been limited prior research investigating the potential clinical relevance of this variability. The purpose of this retrospective study was to assess the prognostic implications of signal intensity on standard imaging techniques for the biologic behavior of skull base chordomas.
\end{abstract}

MATERIALS AND METHODS: Medical records were retrospectively reviewed for 22 patients with pathologically confirmed skull base chordomas. Clinical data were recorded, including the degree of surgical resection, the presence or absence of radiation therapy, and time to progression/recurrence of the tumor or time without progression/recurrence of the tumor following initial treatment. Pretreatment imaging was reviewed for the presence or absence of enhancement and the $\mathrm{T} 2$ signal characteristics. Tumor-to-brain stem signal intensity ratios on $\mathrm{T} 2$, precontrast $\mathrm{T} 1$, and postcontrast $\mathrm{T} 1$ spin-echo sequences were also calculated. Statistical analysis was then performed to assess correlations between imaging characteristics and tumor progression/recurrence.

RESULTS: Progression/recurrence of skull base chordomas was seen following surgical resection in 11 of 14 (78.6\%) patients with enhancing tumors and in zero of 8 patients with nonenhancing tumors. There was a statistically significant correlation between skull base chordoma enhancement and subsequent tumor progression/recurrence $(P<.001)$, which remained significant after controlling for differences in treatment strategy $(P<.001)$. There was also a correlation between postcontrast $\mathrm{Tl}$ signal intensity (as measured by postcontrast $\mathrm{T} 1$ tumor-to-brain stem signal intensity ratios) and recurrence/progression $(P=.02)$. While T2 signal intensity was higher in patients without tumor progression (median tumor-to-brain stem signal intensity ratios on T2 $=2.27$ ) than in those with progression (median tumor-to-brain stem signal intensity ratios on $\mathrm{T} 2=1.78)$, this association was not significant $(P=.12)$.

CONCLUSIONS: Enhancement of skull base chordomas is a risk factor for tumor progression/recurrence following surgical resection.

ABBREVIATIONS: $B S S=$ brain stem signal; $R_{\text {post }}=$ ratio of tumor-to-brain stem postcontrast T1 signal intensity; $R_{\text {pre }}=$ ratio of tumor-to-brain stem precontrast T1 signal intensity; $\mathrm{R}_{\mathrm{T} 2}=$ ratio of tumor-to-brain stem T2 signal intensity; TS = tumor signal

C hordomas are tumors derived from undifferentiated notochordal remnants residing throughout the axial skeleton. ${ }^{1-3}$ Chordomas are relatively rare tumors, accounting for approximately $1 \%-4 \%$ of primary bone tumors, with an incidence of approximately 0.08 per $100,000 .^{4,5}$ Current treatment strategies for chordomas typically consist of surgical resection and adjuvant radiation therapy, with proton beam therapy favored over tradi-

\footnotetext{
Received December 13, 2017; accepted after revision May 11, 2018.

From the Departments of Radiology (E.L., C.D.P.), Pathology (T.S.), Healthcare Policy and Research (Y.Z.), and Neurological Surgery (T.H.S.), New York-Presbyterian Hospital/Weill Cornell Medical Center, New York, New York.

Paper previously presented at: Annual Meeting of the American Society of Head and Neck Radiology, September 16-20, 2017; Las Vegas, Nevada.

Please address correspondence to Eaton Lin, MD, New York-Presbyterian Hospital Weill Cornell Medical Center, Department of Radiology, 525 East 68th St, New York, NY 10065; e-mail: eal9007@med.cornell.edu

http://dx.doi.org/10.3174/ajnr.A5714
}

tional photon therapy. Although chordomas are considered low-grade neoplasms on a histologic basis, most chordomas will recur or progress, regardless of initial treatment strategies. $^{4,6,7}$ The typically insidious clinical course, large tumor burden at the time of diagnosis, and locally aggressive nature of chordomas all pose clinical management difficulties. ${ }^{4,8,9} \mathrm{Me}-$ tastases have also been reported in $7 \%-14 \%$ of cases, most commonly to the lung. ${ }^{10,11}$ Skull base chordomas, which account for approximately $32 \%$ of chordomas, are particularly difficult to treat given their proximity to cranial nerves, the brain stem, and skull base vasculature, and this anatomic site presents more pronounced challenges to gross total resection and radiation therapy. ${ }^{4}$

A variety of prognostic factors has been reported for skull base chordomas, including the degree of surgical resection, tumor size, preoperative Karnofsky Performance Status, type of adjuvant radiation therapy, prior surgical and radiation history, and 
tumor pathology. ${ }^{7,12-23}$ Three pathologic subtypes have been identified-conventional, chondroid, and dedifferentiated-with conventional chordomas the most common and dedifferentiated chordomas the least common and having the least favorable prognosis. ${ }^{12,20,22,24}$ Other factors, such as age and sex, have demonstrated variable associations with outcome. ${ }^{14,18,20-22,25-29}$ However, there is a paucity of research investigating the correlation between imaging features for skull base chordomas and prognosis, or the lack thereof.

The current radiology literature on chordomas has focused mostly on imaging to distinguish chordomas from other differential considerations. ${ }^{30-32}$ On MR imaging examinations, chordomas classically have been described as demonstrating T2 hyperintensity with enhancement on postcontrast imaging. Investigations into diffusionweighted MR imaging characteristics have shown low ADC values for chordomas, particularly when compared with chondrosarcomas, which may otherwise have similar imaging characteristics. ${ }^{33}$ However, chordomas are also known to have marked variability in T2 signal and degree of enhancement. ${ }^{33-35}$ While some studies have posited a correlation between MR imaging characteristics and histologic grade, analyses with larger samples have failed to demonstrate a statistically significant correlation between imaging features and chordoma histology. ${ }^{33,34,36}$

Aside from its standard use as a diagnostic tool, MR imaging has demonstrated prognostic utility for many entities, with extensive literature supporting the use of signal intensity measurements in predicting prognosis for a variety of tumors. ${ }^{37-40}$ However, prior radiology literature addressing skull base chordomas has focused largely on identifying diagnostic imaging features, with only 1 recent study investigating the use of imaging as a prognostic tool. ${ }^{36}$ In this study, we present findings suggesting that enhancement characteristics of skull base chordomas may be predictive of the clinical course.

\section{MATERIALS AND METHODS \\ Overview}

A retrospective study was performed after approval by the institutional review board, with patient privacy protected in accordance with the requirements of the Health Insurance Portability and Accountability Act. Medical records were reviewed for patients with pathologically confirmed skull base chordomas treated at our institution between May 2003 and July 2016. Patients were included in the study only if the following were available for review: pretreatment MR imaging examination, posttreatment MR imaging examinations (remote from the immediate postoperative imaging), operative reports, and pathologic specimens. Using these inclusion and exclusion criteria, we identified a group of 22 patients for this study.

\section{Pathology}

All pathologic specimens were re-analyzed by a neuropathologist with expertise in head and neck tumors, and the diagnosis of chordoma was confirmed in all 22 cases. Classic histopathologic features, including cords and nests of epithelial cells with variable atypia and the presence of physaliphorous cells embedded within an abundant myxoid matrix, were observed in all cases, in addition to an infiltrative growth pattern. Pathologic diagnosis was also confirmed with positive immunohistochemical staining for pan-cytokeratin and epithelial membrane antigen in all cases. Of the 22 cases of chordoma, 8 had chondroid features, 1 was a dedifferentiated subtype, and the remaining 13 cases were the conventional type.

\section{Clinical Data}

Clinical data for these 22 patients were obtained from electronic medical records, with documentation of the degree of surgical resection, the presence or absence of radiation therapy, and time to progression/recurrence or time without progression/recurrence. The degree of surgical resection was categorized as gross total or subtotal on the basis of surgical and radiologic assessments documented in operative reports and immediate postoperative imaging. Nine patients had gross total resections, while 13 had subtotal resections. Sixteen of the 22 patients had adjuvant radiation therapy. Clinical and radiologic follow-up was available for all patients, with a median follow-up time of 28.5 months (range, 2-115 months). Progression and recurrence were defined by imaging assessments, with all except 1 case of progression/ recurrence also having pathologic confirmation of chordoma on repeat resection.

\section{Imaging}

MR imaging examinations were performed on either $1.5 \mathrm{~T}$ or $3 \mathrm{~T}$ magnets. The available pretreatment MR imaging sequences were variable: Twenty patients had postcontrast spin-echo T1 imaging, 18 patients had postcontrast spoiled gradient-echo T1 imaging, 8 patients had precontrast spin-echo T1 imaging, 9 patients had diffusion-weighted imaging, and 12 patients had precontrast spin-echo T2 imaging performed with their available pretreatment MR imaging examinations. Pre- and postcontrast spin-echo T1 imaging was obtained with TRs ranging from 466.7 to $650.0 \mathrm{~ms}$ and TEs ranging from 7.9 to $16.5 \mathrm{~ms}$. Precontrast spin-echo T2 imaging was performed with TRs ranging from 3000.0 to 4483.3 $\mathrm{ms}$ and TEs ranging from 72.0 to $95.0 \mathrm{~ms}$. Diffusion-weighted imaging was not analyzed, given the relatively small number of patients for whom this sequence was available on pretreatment imaging.

For all 22 patients, the presence or absence of tumor enhancement on pretreatment imaging as a dichotomous variable was documented. Subsequently, pretreatment tumor signal intensity on T2 and pre- and postcontrast spin-echo T1 imaging were assessed in patients with available imaging. For the 2 patients without pretreatment postcontrast spin-echo $\mathrm{T} 1$ imaging, pretreatment postcontrast $\mathrm{T} 1$ spoiled gradient-echo images were available for assessing the presence or absence of tumor enhancement, but postcontrast $\mathrm{T} 1$ signal intensity was not measured. By means of the institutional PACS, signal-intensity measurements were made within ROIs selected in each patient's tumor. ROIs were selected on 3 different axial planes for all except 1 patient, for whom 2 axial planes were used due to constraints from smaller tumor size. To account for differences in imaging technique and image noise, we selected a control region within the brain stem on each of these axial images, and a similar technique was used to measure signal intensity in this region of the brain stem. ROIs were selected by drawing the largest possible elliptic area within the tumor or brain 


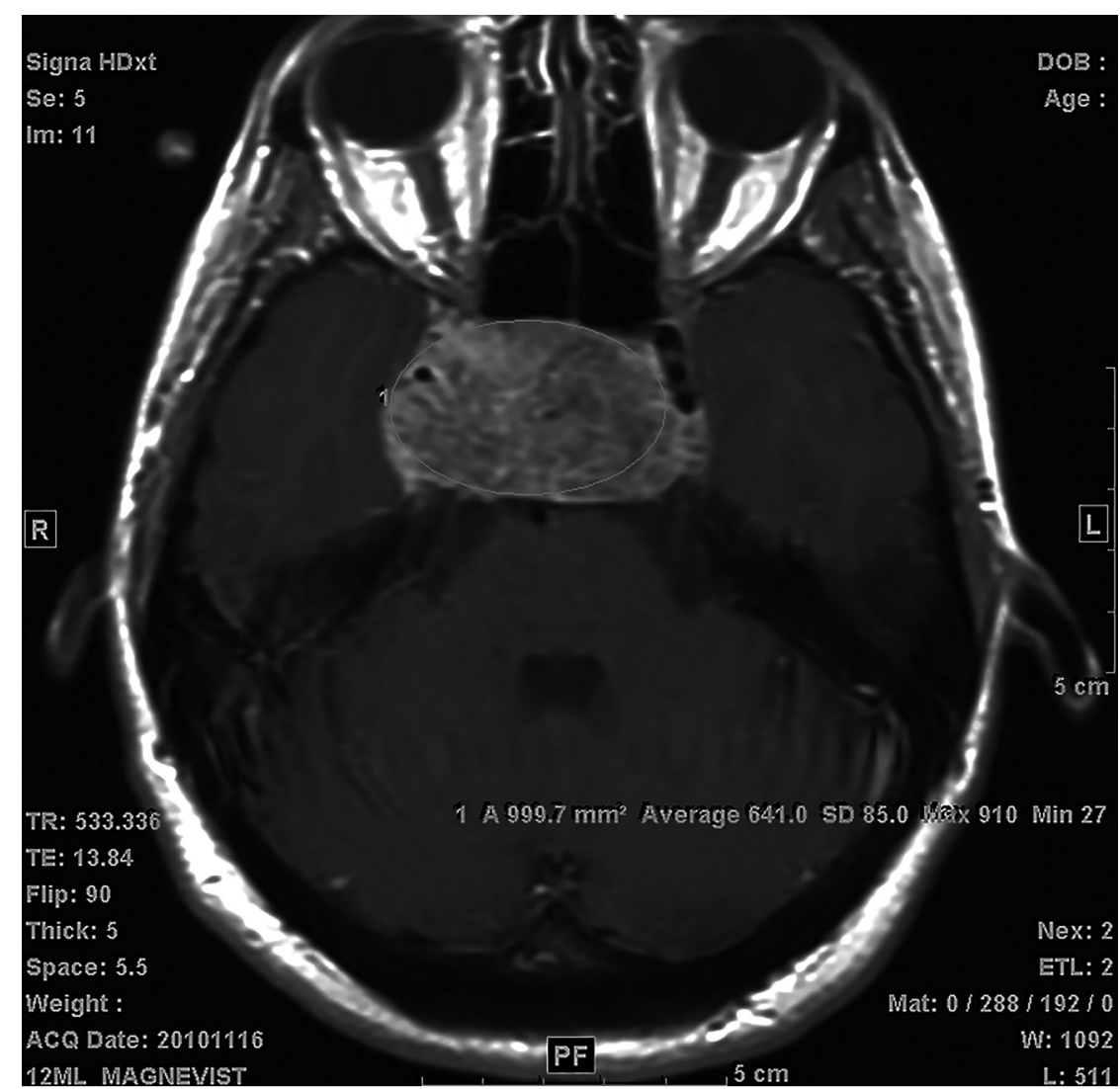

FIG 1. Example of an ROI selection. The largest possible elliptic ROI was drawn within the boundaries of the tumor or brain stem on axial images for average signal intensity measurements. progression was analyzed using a $t$ test. A Wilcoxon rank sum test was used to evaluate whether the groups of patients with and without tumor recurrence/progression had statistically significant differences in $R_{\text {post }}$ and $R_{T 2}$. $\mathrm{R}_{\text {post }}$ was then divided into 3 categories $\left(R_{\text {post }}<1.1, R_{\text {post }}=1.1-1.5\right.$, and $\mathrm{R}_{\text {post }}>1.5$ ), and respective KaplanMeier curves were plotted, with a log-rank test used to assess the overall difference between the degree of enhancement and time without recurrence/progression.

The association between pathologic subtype and the presence or absence of enhancement was analyzed using the Fisher exact test, while the association between subtype and degree of enhancement (as defined by $\mathrm{R}_{\text {post }}$ ) was analyzed using both the $t$ test and the Wilcoxon signed rank test. The Fisher exact test was also used to analyze the association between pathologic subtype and the presence or absence of progression/recurrence, while a Cox model was used to analyze the association between subtype and time to recurrence. stem without incorporating adjacent structures (Fig 1). All ROI signal measurements were performed by a board-certified neuroradiologist with 3 years of experience, blinded to clinical information. Subsequently, measurements in each patient were averaged to obtain the mean tumor precontrast $\mathrm{T} 1$, postcontrast $\mathrm{T} 1$, and $\mathrm{T} 2$ signal ( $\mathrm{TS}_{\text {pre, }}, \mathrm{TS}_{\text {post }}$, and $\mathrm{TS}_{\mathrm{T} 2}$, respectively) and mean brain stem precontrast $\mathrm{T} 1$, postcontrast $\mathrm{T} 1$, and $\mathrm{T} 2$ signal $\left(\mathrm{BSS}_{\text {pre }}, \mathrm{BSS}_{\text {post }}\right.$, and $\mathrm{BSS}_{\mathrm{T} 2}$, respectively). The ratios of tumor signal to brain stem signal were then calculated for T1 precontrast $\left(\mathrm{R}_{\text {pre }}=\mathrm{TS}_{\text {pre }} /\right.$ BSS $\left._{\text {pre }}\right)$, T1 postcontrast $\left(\mathrm{R}_{\text {post }}=\mathrm{TS}_{\text {post }} / \mathrm{BSS}_{\text {post }}\right)$, and $\mathrm{T} 2\left(\mathrm{R}_{\mathrm{T} 2}=\right.$ $\left.\mathrm{TS}_{\mathrm{T} 2} / \mathrm{BSS}_{\mathrm{T} 2}\right)$ imaging.

\section{Statistical Analysis}

Initial statistical analysis was performed with binary categorization of tumor enhancement (present or absent) and tumor recurrence/progression (present or absent). The Fisher exact test was used to analyze the association between tumor enhancement and recurrence/progression. To mitigate bias relating to differential follow-up time (ie, those with more follow-up time have more opportunity to have recurrence/progression), we also repeated the Fisher exact test in a cohort of 16 patients who were followed up for $\leq 50$ months. We re-analyzed the association between tumor enhancement and tumor recurrence/progression, adjusting for treatment strategy (surgical resection alone or surgical resection and radiation therapy).

Ordinal and continuous values for tumor signal and time to tumor recurrence/progression were subsequently analyzed. The association between enhancement and time to recurrence/

\section{RESULTS}

Of the 22 patients with skull base chordomas in this sample, 14 patients had enhancing tumors and 8 patients had nonenhancing tumors (Fig 2). Eleven (78.6\%) of the 14 patients with enhancing tumors had recurrence or progression of tumor, while zero of 8 patients with nonenhancing tumors had recurrence or progression. The association between tumor enhancement and tumor recurrence/progression was statistically significant $(P<.001)$, and the statistical significance remained after restricting the cohort to patients with $\leq 50$ months of follow-up time to mitigate bias related to differential follow-up time $(P=.001)$.

All patients in the sample underwent surgical resection for their skull base chordomas, but 6 of the 22 patients did not undergo adjuvant radiation therapy, 4 of whom had enhancing tumors and 2 of whom had nonenhancing tumors. Given findings in prior studies demonstrating statistically significant correlations between treatment strategies and recurrence/progression of tumor, statistical analysis was also performed adjusting for treatment strategy, which still demonstrated a statistically significant association between enhancement and tumor recurrence $(P<.001)$.

The degree of enhancement, as assessed by $\mathrm{R}_{\text {post }}$ calculations, was higher among patients with recurrence/progression (median $\left.\mathrm{R}_{\text {post }}=1.42\right)$ than in patients without recurrence/progression (median $\left.\mathrm{R}_{\text {post }}=1.05\right)$, with the Wilcoxon rank sum test demonstrating a statistically significant association $(P=.003)$. Based on a $t$ test, there was also a statistically significant correlation between the presence or absence of enhancement and time to recurrence 


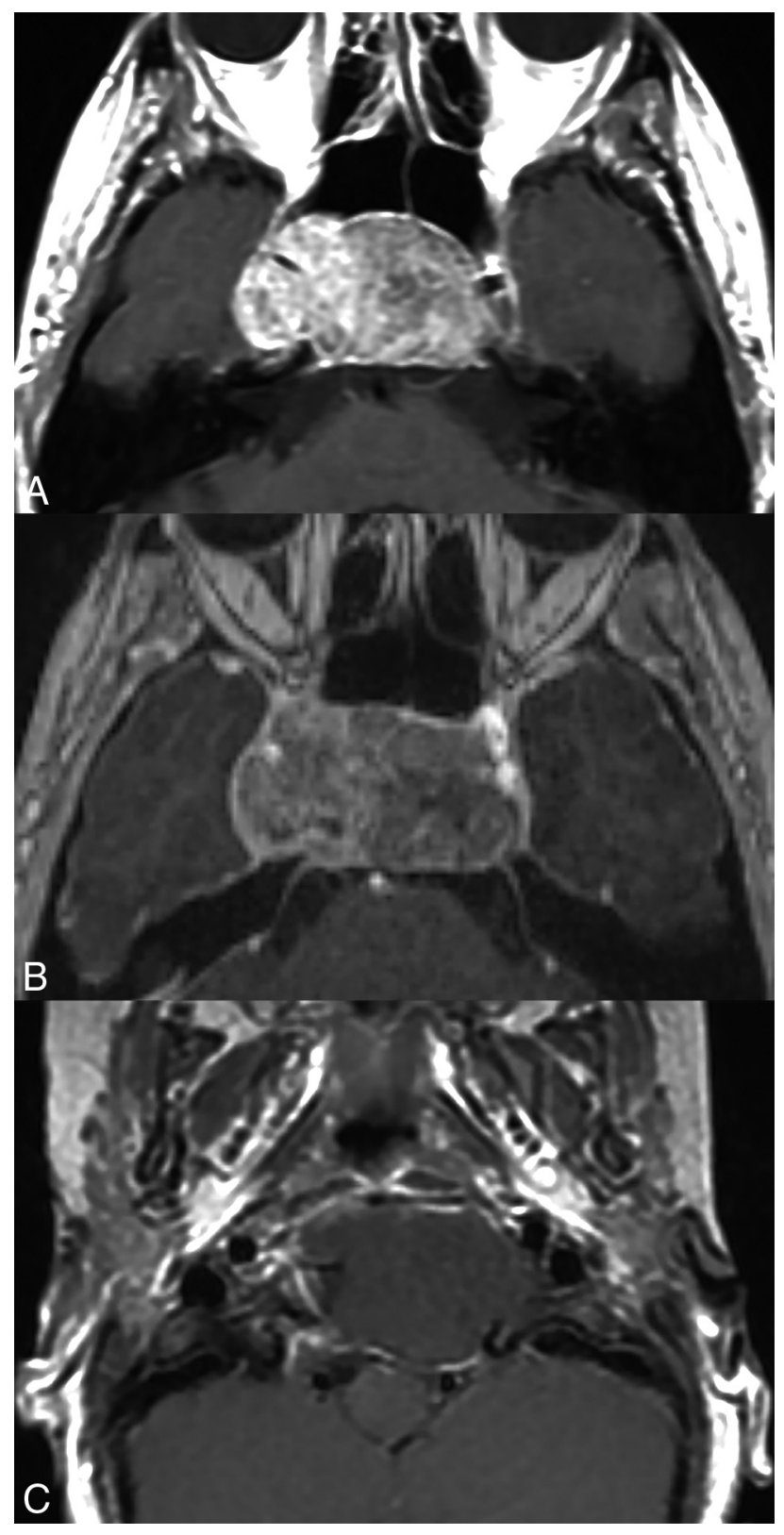

FIG 2. Axial postcontrast T1 images of pathologically proved chordomas, demonstrating a range of enhancement characteristics. Patient 1 (A) had an avidly enhancing chordoma, treated with near-gross total resection and proton beam radiation therapy. Twenty-four-month follow-up (not shown) demonstrated significant progression of tumor, treated with re-resection, but with further progression of tumor 10 months later. Patient $2(B)$ had a heterogeneously enhancing chordoma, treated with near-gross total resection and proton beam radiation therapy. There was progression of the tumor at 29-month follow-up (not shown). Patient 3 (C) had a nonenhancing chordoma, treated with near-gross total resection and proton beam radiation therapy. As of 52-month follow-up (not shown), there has been no evidence of tumor progression.

$(P=.02)$. However, there was no statistically significant correlation between the degree of tumor enhancement and time to recurrence/progression $(P=.30)$.

Finally, there was higher average tumor T2 signal in patients without recurrence/progression (median $\mathrm{R}_{\mathrm{T} 2}=2.27$ ) than in patients with recurrence/progression (median $\mathrm{R}_{\mathrm{T} 2}=1.78$ ), but this association was not statistically significant $(P=.12)$.
Given prior literature reporting a correlation between chordoma subtype and prognosis, ${ }^{20,22,24}$ pathologic subtypes were also documented for each patient. Of the 22 chordomas, 8 were chondroid, 1 was dedifferentiated, and 13 were conventional. There was neither a statistically signification association between chordoma subtype and enhancement $(P=1.0)$ nor a significant association between subtype and degree of enhancement $(P=.81$ using a $t$ test, $P=.78$ using the Wilcoxon signed rank test). While prior literature has shown a relationship between subtype and prognosis, this sample demonstrated no statistically significant association between chordoma subtype and time to recurrence/ progression $(P=.18)$.

\section{DISCUSSION}

Among the 22 patients in this study, there was a statistically significant correlation between the presence of skull base chordoma enhancement and future tumor progression/recurrence $(P<$ $.001)$. This correlation remained statistically significant after restricting the cohort to a 50-month follow-up period to mitigate differential follow-up time bias $(P=.001)$ and demonstrated statistical significance after controlling for differences in treatment strategy $(P<.001)$. While categorization of the chordomas into enhancing and nonenhancing tumors is somewhat subjective, there was also a statistically significant correlation between the intensity of postcontrast T1 signal and recurrence/progression $(P=.02)$. This relationship between chordoma enhancement and future tumor progression/recurrence was also not attributable to previously reported associations between chordoma subtype and prognosis because there was no statistically significant association between subtype and degree of enhancement $(P=.81)$. While average tumor T2 signal intensity was higher in patients without tumor progression than those with progression, this association was not statistically significant $(P=.12)$.

There were several limitations to this study, the foremost being the small sample size. The relative rarity of skull base chordomas limited acquisition of additional patients in a single-center study; a multicenter study would have offered the possibility of an increased sample size but with concomitant limitations from greater heterogeneity in treatment, follow-up, and imaging inherent in any multicenter study.

There were also variations in imaging and treatment that were inherent in a 13-year retrospective study, due to expected changes in MR imaging magnets, imaging parameters, and treatment approaches during such a lengthy timeframe. Notably, proton beam therapy was less frequently used for patients presenting in the earlier part of the study timeframe. The statistical analysis did not control for differences in timeframe; thus, this omission introduced potential bias from any changes in treatment approaches during this period.

Along with the differences in adjuvant radiation therapy, there were also variations in residual tumor volume for patients without gross total resection. The degree of surgical resection is known to affect prognosis and the probability of recurrence for patients with chordomas, ${ }^{17,20}$ so controlling for this variable would have been ideal. However, variable availability and detail of posttreatment medical records precluded correlation with residual tumor volume. 
Given the small sample size of patients and the variable pretreatment imaging acquired for this sample, compromises also had to be made with the study design. For example, assessments of enhancement would ideally be based on differential signal between pre- and postcontrast T1 imaging. However, most patients in this sample were referred for treatment from outside institutions, and the only available pretreatment MR imaging examination for many of these patients was an abbreviated institutional surgical planning MR imaging protocol, which lacks precontrast T1 imaging. Only 8 patients in the sample had precontrast T1 imaging available for signal intensity measurement, requiring an analysis that did not factor in variations in precontrast $\mathrm{T} 1$ signal. For patients in the sample with precontrast $\mathrm{T} 1$ imaging, the SD for intrinsic T1 signal ratio was relatively low $(0.10)$, suggesting that postcontrast $\mathrm{T} 1$ signal was a relatively accurate measure of enhancement; nonetheless, the exclusion of this factor is a limitation, particularly given the known propensity for T1 shortening associated with intratumoral hemorrhage and mucous pools in chordomas. For the 14 patients without institutional pretreatment precontrast T1 spin-echo imaging, there were limitations in distinguishing intrinsic T1 shortening and true enhancement. For 9 of these 14 patients, outside imaging was available for review to confirm true enhancement. However, for 5 patients, the presence or absence of enhancement was determined partly on the basis of outside imaging reports from studies with precontrast T1 imaging; this feature is certainly less than ideal. For 4 of these 5 patients, there was either residual or recurrent tumor, with institutional posttreatment MR imaging demonstrating enhancement characteristics corresponding to those stated in outside pretreatment MR imaging studies, slightly mitigating this limitation.

\section{CONCLUSIONS}

Despite several limitations in this retrospective study, the findings suggest that nonenhancing or minimally enhancing chordomas have a better prognosis than those that show more avid enhancement on pretreatment imaging. There was also a difference in median T2 signal between patients with and without tumor recurrence/progression, but this difference did not demonstrate statistical significance; however, it is certainly possible that a larger sample may demonstrate a significant association between T2 signal and prognosis. Further investigations with a larger sample size are warranted to confirm the prognostic value of skull base chordoma imaging characteristics.

Disclosures: Theodore H. Schwartz-UNRELATED: Consultancy: elliquence; Stock/ Stock Options: Visionsense.

\section{REFERENCES}

1. Vujovic S, Henderson S, Presneau N, et al. Brachyury, a crucial regulator of notochordal development, is a novel biomarker for chordomas. J Pathol 2006;209:157-65 CrossRef Medline

2. Salisbury JR, Deverell MH, Cookson MJ, et al. Three-dimensional reconstruction of human embryonic notochords: clue to the pathogenesis of chordoma. J Pathol 1993;171:59-62 CrossRef Medline

3. Choi KS, Cohn MJ, Harfe BD. Identification of nucleus pulposus precursor cells and notochordal remnants in the mouse: implications for disk degeneration and chordoma formation. Dev Dyn 2008;237:3953-58 CrossRef Medline

4. McMaster ML, Goldstein AM, Bromley CM, et al. Chordoma: inci- dence and survival patterns in the United States, 1973-1995. Cancer Causes Control 2001;12:1-11 CrossRef Medline

5. Healey JH, Lane JM. Chordoma: a critical review of diagnosis and treatment. Orthop Clin North Am 1989;20:417-26 Medline

6. Chambers KJ, Lin DT, Meier J, et al. Incidence and survival patterns of cranial chordoma in the United States. Laryngoscope 2014;124: 1097-102 CrossRef Medline

7. Tzortzidis F, Elahi F, Wright D, et al. Patient outcome at long-term follow-up after aggressive microsurgical resection of cranial base chordomas. Neurosurgery 2006;59:230-37 CrossRef Medline

8. Bergh P, Kindblom LG, Gunterberg B, et al. Prognostic factors in chordoma of the sacrum and mobile spine: a study of 39 patients. Cancer 2000;88:2122-34 Medline

9. Chugh R, Tawbi H, Lucas DR, et al. Chordoma: the nonsarcoma primary bone tumor. Oncologist 2007;12:1344-50 CrossRef Medline

10. Young VA, Curtis KM, Temple HT, et al. Characteristics and patterns of metastatic disease from chordoma. Sarcoma 2015;2015: 517657 CrossRef Medline

11. Heffelfinger MJ, Dahlin DC, MacCarty CS, et al. Chordomas and cartilaginous tumors at the skull base. Cancer 1973;32:410-20 Medline

12. Rosenberg AE, Brown GA, Bhan AK, et al. Chondroid chordoma: a variant of chordoma- a morphologic and immunohistochemical study. Am J Clin Pathol 1994;101:36-41 CrossRef Medline

13. Safwat A, Nielsen OS, Jurik AG, et al. A retrospective clinicopathological study of 37 patients with chordoma: a Danish national series. Sarcoma 1997;1:161-65 CrossRef Medline

14. Benk V, Liebsch NJ, Munzenrider JE, et al. Base of skull and cervical spine chordomas in children treated by high-dose irradiation. Int $J$ Radiat Oncol Biol Phys 1995;31:577-81 CrossRef Medline

15. Berven S, Zurakowski D, Mankin HJ, et al. Clinical outcome in chordoma: utility of flow cytometry in DNA determination. Spine (Phila Pa 1976) 2002;27:374-79 CrossRef Medline

16. Borba LA, Colli B, Al-Mefty O. Skull base chordomas. Neurosurgery Quarterly 2001;11:124-39 CrossRef

17. Colli B, Al-Mefty O. Chordomas of the craniocervical junction: follow-up review and prognostic factors. J Neurosurg 2001;95:933-43 CrossRef Medline

18. Crockard HA, Steel T, Plowman N, et al. A multidisciplinary approach to skull base chordomas. J Neurosurg 2001;95:175-83 CrossRef Medline

19. Kaneko Y, Sato Y, Iwaki T, et al. Chordoma in early childhood: a clinicopathological study. Neurosurgery 1991;29:442-46 CrossRef Medline

20. Wu Z, Zhang JT, Zhang LW, et al. Prognostic factors for long-term outcome of patients with surgical resection of skull base chordomas: 106 case review in one institution. Neurosurg Rev 2010;33:451-56 CrossRef Medline

21. Bohman LE, Koch M, Bailey RL, et al. Skull base chordoma and chondrosarcoma: influence of clinical and demographic factors on prognosis-a SEER analysis. World Neurosurg 2014;82:806-14 CrossRef Medline

22. Zou MX, Lv GH, Zhang QS, et al. Prognostic factors in skull base chordoma: a systematic literature review and meta-analysis. World Neurosurg 2018;109:307-27 CrossRef Medline

23. Zhai $Y$, Bai J, Gao H, et al. Clinical features and prognostic factors of children and adolescents with clival chordomas. World Neurosurg 2017;98:323-28 CrossRef Medline

24. Jian BJ, Bloch OG, Yang I, et al. Adjuvant radiation therapy and chondroid chordoma subtype are associated with a lower tumor recurrence rate of cranial chordoma. J Neurooncol 2010;98:101-08 CrossRef Medline

25. Mitchell A, Scheithauer BW, Unni KK, et al. Chordoma and chondroid neoplasms of the spheno-occiput: an immunohistochemical study of 41 cases with prognostic and nosologic implications. Cancer 1993;72:2943-49 Medline

26. Dorfman HD, Czerniak B. Bone cancers. Cancer 1995;75(1 Suppl): 203-10 Medline

27. Forsyth PA, Cascino TL, Shaw EG, et al. Intracranial chordomas: a 
clinicopathological and prognostic study of 51 cases. J Neurosurg 1993;78:741-47 CrossRef Medline

28. Soo MY. Chordoma: review of clinicoradiological features and factors affecting survival. Australas Radiol 2001;45:427-34 CrossRef Medline

29. Thieblemont C, Biron P, Rocher F, et al. Prognostic factors in chordoma: role of postoperative radiotherapy. Eur J Cancer 1995; 31A:2255-59 CrossRef Medline

30. Lang N, Su MY, Xing X, et al. Morphological and dynamic contrast enhanced MR imaging features for the differentiation of chordoma and giant cell tumors in the axial skeleton. J Magn Reson Imaging 2017;45:1068-75 CrossRef Medline

31. Si MJ, Wang CS, Ding XY, et al. Differentiation of primary chordoma, giant cell tumor and schwannoma of the sacrum by CT and MRI. Eur J Radiol 2013;82:2309-15 CrossRef Medline

32. Tsuji $\mathrm{T}$, Chiba K, Watanabe $\mathrm{K}$, et al. Differentiation of spinal giant cell tumors from chordomas by using a scoring system. Eur J Orthop Surg Traumatol 2016;26:779-84 CrossRef Medline

33. Yeom KW, Lober RM, Mobley BC, et al. Diffusion-weighted MRI: distinction of skull base chordoma from chondrosarcoma. AJNR Am J Neuroradiol 2013;34:1056-61 CrossRef Medline

34. Pamir MN, Ozduman K. Analysis of radiological features relative to histopathology in $\mathbf{4 2}$ skull-base chordomas and chondrosarcomas. Eur J Radiol 2006;58:461-70 CrossRef Medline

35. Erdem E, Angtuaco EC, Van Hemert R, et al. Comprehensive review of intracranial chordoma. Radiographics 2003;23:995-1009 CrossRef Medline

36. Tian $\mathrm{K}$, Wang $\mathrm{L}, \mathrm{Ma} J$, et al. MR imaging grading system for skull base chordoma. AJNR Am J Neuroradiol 2017;38:1206-11 CrossRef Medline

37. Pope WB, Sayre J, Perlina A, et al. MR imaging correlates of survival in patients with high-grade gliomas. AJNR Am J Neuroradiol 2005; 26:2466-74 Medline

38. Hilario A, Sepulveda JM, Perez-Nuñez A, et al. A prognostic model based on preoperative MRI predicts overall survival in patients with diffuse gliomas. AJNR Am J Neuroradiol 2014;35:1096-102 CrossRef Medline

39. Valles FE, Perez-Valles CL, Regalado S, et al. Combined diffusion and perfusion MR imaging as biomarkers of prognosis in immunocompetent patients with primary central nervous system lymphoma. AJNR Am J Neuroradiol 2013;34:35-40 CrossRef Medline

40. Pope WB, Lai A, Mehta R, et al. Apparent diffusion coefficient histogram analysis stratifies progression-free survival in newly diagnosed bevacizumab-treated glioblastoma. AJNR Am J Neuroradiol 2011;32:882-89 CrossRef Medline 